Article

\title{
An Empirical Study on Online Learners' Continuance Intentions in China
}

\author{
Yiwen Li *(D), Norihiro Nishimura (D), Hisanori Yagami and Hye-Sook Park \\ Graduate School of Regional Innovation Studies, Mie University, 1577 Kurimamachiya-cho, Tsu, \\ Mie-Prefecture 514-8507, Japan; nishimura.norihiro@mie-u.ac.jp (N.N.); yagami@crc.mie-u.ac.jp (H.Y.); \\ park@mie-u.ac.jp (H.-S.P.) \\ * Correspondence: 618d0s2@m.mie-u.ac.jp
}

Citation: Li, Y.; Nishimura, N.;

Yagami, H.; Park, H.-S. An Empirical Study on Online Learners'

Continuance Intentions in China.

Sustainability 2021, 13, 889.

https://doi.org/10.3390/su13020889

Received: 7 December 2020

Accepted: 13 January 2021

Published: 17 January 2021

Publisher's Note: MDPI stays neutral with regard to jurisdictional clai$\mathrm{ms}$ in published maps and institutional affiliations.

Copyright: $(\odot 2021$ by the authors. Licensee MDPI, Basel, Switzerland. This article is an open access article distributed under the terms and conditions of the Creative Commons Attribution (CC BY) license (https:// creativecommons.org/licenses/by/ $4.0 /)$.

\begin{abstract}
Online education in China is developing at a rapid pace due to its unique advantages, and its sustainable development is becoming increasingly crucial. Thus, this study attempted to understand learners' continuance intentions in an online learning environment and examined the factors influencing online learners' continuous retention. The research model for the influencing factors and study hypotheses were constructed based on multiple theoretical and synthesized perspectives, such as the information system success model; interactions between students, content, and instructors; and the theory of perceived value. To achieve the stated objectives, we conducted a questionnaire survey, in which 382 valid responses were collected from Chinese respondents from 32 provinces in China in April and May 2020. Furthermore, this study primarily employed Structural Equation Modeling (SEM) and Partial Least Squares Structural Equation Modeling (PLS-SEM) to test the constructed model. The results indicate that service quality, course quality, and student-instructor interaction have indirect and positive effects on learners' continuance intentions for online learning, while the variable of perceived value is a significant mediator for online learners' retention and has a direct influence on their continuance intentions. Student-student interaction and student-content interaction do not have direct or indirect effects on online learners' continuance intentions.
\end{abstract}

Keywords: continuance intention; online learning; perceived value; student-student interaction; student-instructor interaction; student-content interaction

\section{Introduction}

The United Nations formulated the Sustainable Development Goals (SDGs), which are a collection of 17 long-term development objectives, to replace the Millennium Development Goals and serve as the guiding spirit of global development work from 2015 to 2030 [1]. The 17 goals are about taking the path of sustainable development and addressing development issues in social, economic, and environmental areas [2]. Among them, SDG 4 is dedicated to ensuring inclusive and equitable quality education and promoting lifelong learning opportunities for all. Acquiring high-quality education is the basis for improving people's lives and for achieving sustainable development.

As one of the most significant components of quality education, online education has unique characteristics that facilitate the sustainable development of education, such as low cost, convenience, flexibility, repetition, high efficiency, a low threshold, rich teaching resources, and broadly accessible user groups. These points provide e-learning with an edge over the traditional classroom setting [3]. Likewise, online education has the potential to offer learning opportunities to new learners and fundamentally transform learning delivery and the competitive environment. Online learning breaks through the constraints of time and place by providing learning experiences to distant learners and allowing flexible learning modes so that learners can freely select and pace their learning paths in accordance with their real conditions, and benefit from contingent teaching [4]. The concept and pattern of online education have changed dramatically from the distance education 
model at the end of the 20th century to the current popular online education model. It has also gradually transformed from the sharing of static resources to the use of interactive, open classrooms and online learning.

In recent years, the online education model has been continuously upgraded with the help of information technology. With the launch of the $4 \mathrm{G}$ network and the popularity of smartphones, phone applications have become convenient, easy-to-use learning tools. Similarly, various online education platforms are constantly emerging. Statistics from the professional website e-student.org show that the corporate e-learning sector is expected to grow by as much as USD 38 billion from 2020 to 2024. Major EdTech companies, such as Coursera, are already valued at well over USD 1 billion, and will be the driving force of the entire online education industry [5]. Meanwhile, according to iResearch data, the scale of China's online education market exceeded RMB 320 billion in 2019, with a 28.1\% year-on-year increase. Higher education and vocational training accounted for $74.6 \%$ of this figure, and K12 education accounted for $21.3 \%$. Thus, the online education market is still dominated by adult education, but the share of K12 education is growing. It is also expected that the growth rate of the market will remain between 19 and $24 \%$ for the next three years [6].

However, with the rapid development of online education, the problems of high dropout rates and the low retention of online learners have become increasingly prominent. The dropout rate at the Open University, a renowned online educational institution in the UK, was up to 78\% according to statistics in 2010 [7]. Data from a survey conducted by Duke University in North Carolina showed that the dropout rates for Massive Open Online Courses (MOOCs) were up to 90\% [8]. A report on the development of online education in the United States stated that a high dropout rate was the primary obstacle to the future growth of online education [9]. Thus, this study aimed to explore the factors that influence learners' continuous use of online education and put forward corresponding countermeasures to promote the sustainable development of online education in China. Specifically, we explored three research questions:

(1) What are the main factors that influence learners' continuance intentions in an online education environment?

(2) Are all our hypotheses valid? How can the results be explained?

(3) What are our recommendations for the improvement of the online education environment?

The second research question relates to the nine hypotheses that we framed to predict the determinants of online learning continuance intention. Furthermore, the validity of the hypotheses was verified, and correlations were demonstrated.

To address the research questions in this study, an online survey was conducted, and 382 valid responses were collected from Chinese respondents from 32 provinces in China in April and May 2020. Additionally, statistical analysis was conducted using Structural Equation Modeling (SEM) and Partial Least Squares Structural Equation Modeling (PLSSEM) to verify the reasonability of the constructed model. The principal conclusions are as follows: service quality, course quality, and student-instructor interaction indirectly influence online learners' continuance intentions, while perceived value is a significant mediator with a direct influence on online learners' continuance intentions. However, student-student interaction and student-content interaction do not have direct or indirect effects on online learners' continuance intentions.

The rest of the paper is composed of five sections that are arranged as follows. Section 2 describes the literature review, which primarily introduces theories and definitions of concepts such as online education, the information systems success model, perceived value, interaction, and continuance intention. Section 3 outlines the nine hypotheses and the research model constructed to determine the factors that influence learners' motivations for continuing in an online learning environment. This section also describes the questionnaire design and content as well as the data analyses and hypothesis test results. In Section 4, the discussion is presented; the implications of this study are outlined in 
Section 5. This section also highlights some limitations of this study and recommendations for future studies.

\section{Literature Review}

\subsection{An Overview of Online Learners' Continuance Intentions}

Previous studies have identified critical variables for analyzing online learning continuous retention, and the frequently adopted theoretical perspectives in this field are the technology acceptance model (TAM), expectation confirmation model (ECM), and information system (IS) success model. A wide arsenal of research in this area involves an extension or the combination of these theories. Lee M.C. synthesized the ECM, TAM, theory of planned behavior (TPB), and flow experience to construct the hypotheses model and analyzed online learners' continuous use. The ECM proposed three variables—satisfaction, confirmation, and post-adoption expectations - to explain learners' continuous usage of online learning platforms. However, learners' behavioral intentions toward online learning systems are also affected by other factors; therefore, this study used multiple theories to bridge the gaps that would otherwise have remained had each theory been considered independently [10].

The IS success model tends to emphasize the significance of technology in dealing with learners' behavioral intentions, and many prior studies have constructed hypotheses on online learning behavior, based on the IS success model. Dağhan et al. combined technology continuance theory, the IS success model, the cognitive model, and the IS ECM to construct their integrated model. They argued that online learning environment usage could be confirmed by system quality, service quality, and information quality variables [11]. Aldholay et al. designed an extended IS success model in which transforming leadership plays the role of a mediator between perceived quality and actual use in the context of Yemen [12]. Mohammadi integrated the IS success model and TAM to predict e-learning outcomes regarding users' intentions in Iran. They found that system quality and information quality were the significant factors driving learners' use of e-learning, and perceived learning assistance was also affected by satisfaction and intention [13]. However, most studies that implement the IS success model seem to concentrate on the variables in the technology dimension and individuals' experience, and neglect the evaluation of other environmental intervening variables, such as perceived interactivity. Therefore, our study explored online learning behavioral intentions by combining the IS success model with interaction theory.

We synthesized these two theoretical perspectives for three reasons. First, the IS success model is widely adopted in exploring continuous IS usage, but it concentrates on the overall quality of IS; other variables, such as e-learning environmental opinions, are hardly mentioned. Although many scholars have explored other variables-such as perceived ease of use, perceived usefulness, confirmation, and outcome expectations when considering the IS success model-interactions between students, instructors, and content are seldom examined. Thus, we combined these two theoretical perspectives to analyze continued online learning adoption.

Second, learners' perceived interactions with others are an essential factor in the elearning environmental dimension when we consider online learners' behavioral intentions [14]. However, most studies on interactions in this area merely mention the concept of "interaction" and seldom explore its three dimensions-between students, instructors, and content-concretely. Liu et al. conducted research on learners' continuous retention in one-to-one online learning, in which instructor-learner interaction was primarily examined, and interaction feedback was found to be significant for online learning outcomes [15]. Liu I.F. et al. extended the TAM model to explore the factors that affect the intention to use in an online learning community, and used perceived interaction as one of the variables that facilitate better learning outcomes [16]. As for the literature on multi-dimensional interaction, Moore G. examined the significant role of interactions between students, instructors, and content because improving cooperation and communication with online learners was one of the 
indicators for the success of an online learning environment [11,17]. You et al. investigated the influence of student-student interaction, student-instructor interaction, and student-content interaction on online learning retention from the perspective of the moderation and mediation of academic emotions [18]. Hone reported the factors affecting MOOC retention and found that MOOC course content and interaction with instructors were significant predictors for MOOC retention, mediated by the perceived effectiveness of the course [19]. Although these studies considered multi-dimensional interaction in an online learning community, most of them only focused on student-instructor interaction or student-student interaction, and they have been quite silent on the integration of three-dimensional interaction and other variables. Thus, the integration of these two perspectives related to technical and environmental dimensions provided an answer to the knowledge gap.

Third, the ECM and IS success model posit a significant association between satisfaction and behavior intention $[10,13]$. Thus most of the studies adopting these two theories primarily view satisfaction as the mediator or a significant variable. Brady and Robertson stated that perceived value was the primary factor influencing purchase intentions in the study of service value in the USA and educators [20]. Dağhan et al. explored continuous intention towards online learning usage and proposed a model to explain the determinants of it. They also suggested an association between overall quality variables, perceived value, and continuance intention in online learning [10]. Therefore, this study adopted perceived value as a mediating variable to construct hypotheses and the model.

\subsection{Online Education}

Today, people are living in an era of information explosion and the age of the knowledge economy, wherein knowledge plays a leading role in the whole production process. The effective acquisition of knowledge is vital for improving business competitiveness and for the realization of individual value. With the growing popularity of the Internet, there has been a digital revolution that has brought along many new platforms and conveniences such as email, e-shopping, e-working, and e-education [21]. E-education, or online education, is one method used to increase knowledge and skills through information and communication technology. As a new mode of education, online learning provides an opportunity for the reform of and innovation in the education sector, with its open, personalized, and networking characteristics. The emergence of online education provides a feasible way to optimally allocate educational resources and provide people in underdeveloped areas with opportunities to access such resources.

The online learning market has been expanding at a swift pace in recent years because of the rapid development of information and communication technology, and changes in people's lifestyles, especially due to the global coronavirus (COVID-19) outbreak in 2020. The pandemic accelerated the growth of the number of online learners. According to the 45th China Statistical Report on Internet Development, the number of online learners in March 2020 in China reached 422.96 million, accounting for $46.8 \%$ of the total netizens. With regard to the usage of Internet access devices, about $99 \%$ use mobile phones to surf the Internet; the number of mobile phone online learners has reached 420.23 million, accounting for $46.9 \%$ of the total mobile phone users in China. The global online learning industry is increasing with an annual growth rate of around $19 \%$ and is projected to be worth USD 243 billion in the next two years. The United States dominates the global online education market. However, regions such as Europe, Latin America, and Asia are also starting to become increasingly important players in the industry [5].

Although the student number and market scale are growing rapidly, there is also a growing concern over the issue of high dropout rates in the online learning environment [22]. MOOC College, the largest Chinese MOOC learning community in the world, launched a survey of Chinese MOOC learners for three consecutive years, from 2013 to 2015. The results showed that the dropout rate in China is roughly equal to that of other countries. They also revealed that the MOOC completion rate is less than 10\% [23]. According to the MOOC learners' survey in 2014, the MOOC user base increased from 130,000 to 650,000, but the 
dropout rate was still high. At least half of the registered students did not attend classes, and only about half of the students who attended classes eventually completed courses.

\subsection{Information Systems Success Model}

After summarizing and analyzing theoretical and empirical information system research conducted by many scholars, Delone and McLean proposed the IS success model, which was used to interpret the success of IS under various conditions [24,25]. Delone and McLean divided IS success into six dimensions: system quality, information quality, use, user satisfaction, individual impact, and organizational impact [26]. Seddon revised the model, preserving most of the elements of Delone and McLean's model, while using "usefulness" as the mediator [27]. User satisfaction also contributes to continuance intentions toward a system, while IS success benefits individuals, organizations, and society.

Delone and McLean revised the model proposed in 1992, adding a new dimension of service quality $[11,25,28]$. In the process of implementing an IS, users consider not only the system but also the services. Therefore, service quality also facilitates the success of an IS. The concept of usage intention was also involved in the model. Since the IS success model was put forward, it has been widely used in the application and verification of enterprise and government information systems. Consequently, the model has evolved and is now composed of six dimensions: system quality, information quality, service quality (SQ), intention to use, user satisfaction, and net benefits $[28,29]$.

With regard to the first three dimensions of the IS success model, system quality refers to the technical efficacy of the concerned system in terms of ease of use, functionality, reliability, flexibility, data quality, portability, integration, and importance; information quality is correlated with semantic success and system outputs in terms of accuracy, timeliness, relevance, and consistency; and service quality is characterized by the support users get from the IS department, such as empathy from personnel and responsibility [25,27,28].

\subsection{Interaction}

Interaction has long been viewed as a crucial component in the field of education. It is a concept introduced from social psychology into the field of teaching. Although this concept does not have a clear and widely accepted definition, the essential characteristic of interaction or interactivity is reciprocal behaviors that involve two or more subjects and their dealings. Interaction in education refers to the reciprocal behavior between the learner and the learning environment, which can be described as an instructional interaction in the educational environment $[30,31]$. Instructional interaction is aimed at helping learners to change and achieve their goals [32]. Moore, G. listed three types of interactions in distance education: student-student (SS) interaction, student-instructor (SI) interaction, and student-content (SC) interaction [17]. No single medium is superior to another in terms of supporting educational experiences. SI interaction currently has the highest perceived value among students and thus commands competitive market value [30]. Additionally, SI interaction can offer assistance that is emotional, organizational, and instructional in nature [33]. SC interaction is characterized by learners' internal didactic conversation or "talking to themselves" when they interact with textbooks, lectures, or other content. This type of interaction is dependent on the self-motivation capability of the student. SS interaction is sometimes an extremely important resource for learning. A group of fellow learners is invaluable to both learners and instructors in application and evaluation.

\subsection{Perceived Value}

Perceived value (PV) was first proposed as an economic concept, but it is also regarded as an essential competitive strategy [34]. This concept can be defined as the consumer's evaluation of the utility of a product or service based on perceptions of what is received and what is given [35]. Perceived value is often considered an equity concept, referring to the evaluation of the fairness, utility, or perceived cost of the offering [34,36]. Different values can be perceived by customers, such as functional value, social value, emotional value, 
epistemic value, and conditional value [37]. For this investigation, perceived value is defined as consumers' overall assessment of what is received relative to what is given $[38,39]$. Although it is considered an economic concept, perceived value can also be utilized in other fields such as online education because it is context specific and varies across service settings and individuals. Babin et al. classified perceived value into two types: hedonic and utilitarian. The hedonic value is the value of enjoyment [40].

Many scholars have conducted studies on the dimension of perceived value. Zeithaml et al. considered consumers' perceived value as the trade-off between perceived benefits and perceived sacrifice, thus producing an overall evaluation of the utility of a product or service $[35,41]$. Mizik and Jacobson hold the view that perceived value is the core consequence of marketing activities in that it is crucial for acquiring long-term business success [42].

Consumers are transforming from material consumption to a mode with the new connotations and characteristics of emotional and spiritual consumption. Perceived value is considered a significant factor in attracting and retaining consumers in this transformation process, so it is a significant sector in enterprises' strategy.

\subsection{Continuance Intention}

Intention is interpreted as an individual's views or ideas on things, resulting in subjective thinking. There is no unified definition of this concept in relevant research on continuance intention. Continuous use behavior depends on users' continuance intentions (CIs). Bhattacherjee employed the expectation confirmation theory to further interpret and comprehend this concept [43]. Expectation confirmation theory is widely applied in the literature on consumer satisfaction, purchase intentions, and brand promotion. The initial acceptance of online learning is the first step in receiving online education. Only when learners have the intention to continue participating in learning activities can online learning play its commercial and educational role effectively. The issues of high dropout rates and low completion rates have restricted the sustainable development of online education. Hence, the CIs of online learners have been viewed as a crucial driver in promoting the development of online education.

\section{Research Methodology}

\subsection{Research Model}

Based on existing theories and research related to online learning continuance intentions described in Section 2, nine research hypotheses were constructed (as shown in Figure 1), which indicate the factors of and mediators for online learners' continuance intentions.

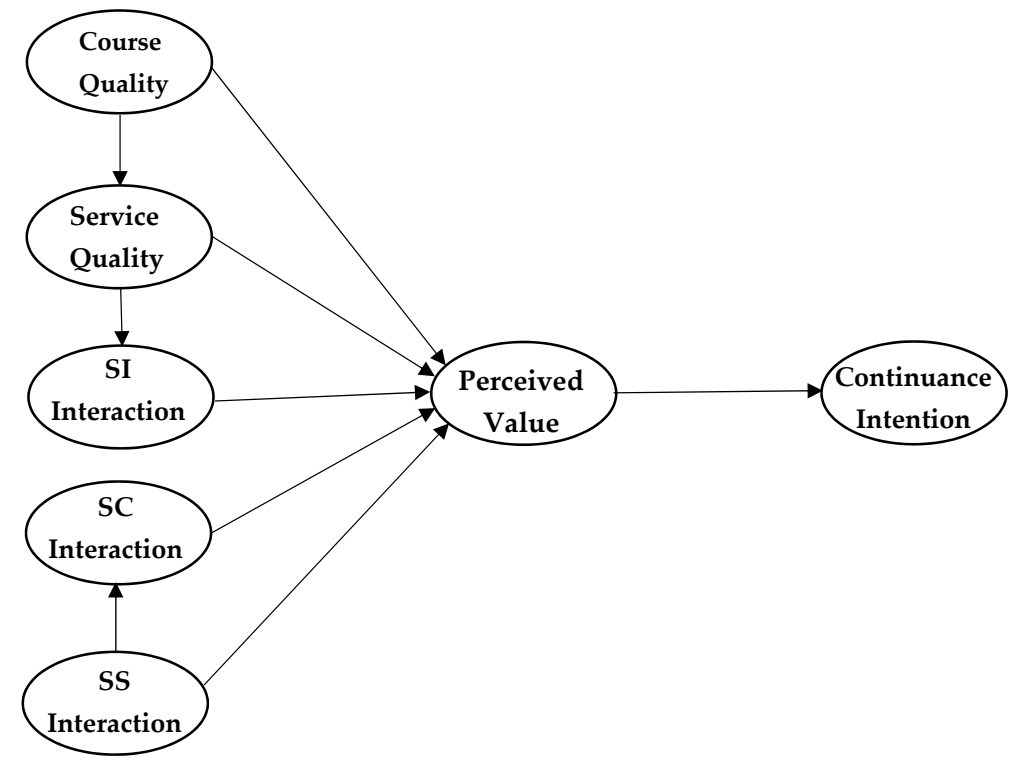

Figure 1. Research model for continuance intentions toward online education. 


\subsection{Research Hypotheses}

This study primarily adopted the information systems (IS) success model and the concept of interaction to explore the variables influencing learners' perspectives about online education. Among the six dimensions of the IS success model, course quality refers to the quality of e-learning system outputs, which include course knowledge and the authority of teaching content [28]. Information quality captures the content issue of the information system [25]. Hence, course quality and information quality have similar connotations. In this study, course quality (CQ) replaced information quality in order to emphasize its pedagogical implications because the quality of well-designed courses is considered more crucial in the context of online education [14]. As a crucial dimension of perceived quality, service quality, which refers to the whole gamut of support received from the service provider, has started playing an increasingly significant role [25]. Broadly speaking, the improvement of course quality plays a considerable role in optimizing service quality. In this case, there is an intimate correlation between course quality and service quality. Therefore, a relationship between course quality and service quality is proposed in Hypothesis 1.

Hypothesis 1 (H1). Course quality has a positive effect on service quality.

The interaction between human beings and the environment is considered a crucial aspect in understanding an individual completely [44]. Students view student-instructor (SI) interaction as the most reliable element [30]. Furthermore, service quality is characterized by the overall support that users get from support providers, including support received from online learning platforms or systems [29]. High levels of service quality from support providers promote smoother interactions between students and instructors. Therefore, the hypothesis on the relationship between service quality and student-instructor interaction is as follows:

Hypothesis 2 (H2). Service quality has a positive effect on SI interaction.

Anderson suggested that developments in information technology, improvements in storage capabilities, and increases in functionality offer the opportunity to transform student-student (SS) interaction and student-instructor (SI) interaction into enhanced modes of student-content (SC) interaction [30]. In the context of a new technical revolution, student-student interaction enables students to understand the learning content in a more intellectual way and gradually change their cognitive structure. Therefore, the hypothesis on the relationship between student-student interaction and student-content interaction is as follows:

Hypothesis 3 (H3). SS interaction has a positive effect on SC interaction.

Zeithaml believed that consumers' perceived value is their overall perception of products based on a cost-benefit analysis [35]. Patterson and Spreng pointed out that the comprehensive trade-off between perceived gains and losses is the essence of consumers' perceived value in their comprehensive evaluation of products and services [41]. When learners select an online course to pursue, course quality is one of the important issues to be considered. At the same time, course quality also has a significant influence on learners' decisions regarding whether to continue online learning after a period of time. As course quality increases, online learners' perceived value of courses is likely to increase, which facilitates their retention in online courses. Therefore, the hypothesis on the relationship between course quality and learners' perceived value is as follows:

Hypothesis 4 (H4). Course quality has a positive effect on learners' perceived value.

Sassere et al. observed that service quality includes two parts, the service results and the method of providing services [45]. Roca et al. held a view that service quality is intimately correlated with confirmation and, thereby, the perceived usefulness of online education [46]. Wang et al. suggested that service quality influences perceived value 
and user satisfaction, which also affects learners' loyalty and continuance intentions [47]. Consequently, the hypothesis on the relationship between service quality and learners' perceived value is as follows:

Hypothesis 5 (H5). Service quality has a positive effect on learners' perceived value.

Interaction implies mutual exchange among human beings or between humans and content that may include knowledge [47]. Based on this perspective, three types of interactions in the context of online education are proposed: SI interaction, SC interaction, and SS interaction. Interaction in online courses allows students to be participants rather than listeners, which prompts students to increase their perceived value of courses. As a result, the hypotheses on the relationships between the three types of interactions and learners' perceived value are as follows:

Hypothesis 6 (H6). SI interaction has a positive effect on learners' perceived value.

Hypothesis 7 (H7). SC interaction has a positive effect on learners' perceived value.

Hypothesis 8 (H8). SS interaction has a positive effect on learners' perceived value.

Tam, J.L.M. provides evidence that perceived value is more effective than consumption in stimulating consumers' purchase intentions and purchase behavior, and it plays a significant mediating role in the model [20]. Woodruff, Flint, and Gardial state that value can be approached in three different directions: values, desired values, and value judgments. In the online education environment, the category of value judgments implies learners' perceived value of online courses [48]. In this case, the higher the perceived value of a product or service is, the stronger the willingness to continue using that product or service is [49]. Thus, the hypothesis on the relationship between perceived value and learners' continuance intentions is as follows:

Hypothesis 9 (H9). Perceived value has a positive effect on learners' continuance intentions.

\subsection{Questionnaire Content and Composition of Respondents}

The questionnaire, which was designed based on existing questionnaires and literature, comprised 7 constructs and 27 related items. The questionnaire was distributed as an online survey hosted by a professional online survey platform (https: / /www.wjx.cn). Data were collected from 399 respondents living in China in April and May 2020, but 17 responses were determined to be invalid because they included doubtful answers or were provided by respondents with no e-learning experience. Thus, survey data from 382 respondents were considered to be valid and utilized in this study. These respondents were all Chinese, came from 32 provinces across the country, and had previous online learning experience. The questionnaire scale was designed using a five-point Likert scale, with the response options from 1 to 5 being "Strongly Disagree", "Disagree", "Neutral", "Agree", and "Strongly Agree", indicating the degree of agreement [50]. Table 1 summarizes the demographic profile of the respondents to the online survey. Specifically, it can be seen that about $62.57 \%$ of the respondents were women and around 37.43\% men. Most of the respondents were between the ages of 18 and 25. As for occupation, most of the participants were students because they had more free time and a need for online education. It is worth noting that undergraduate students accounted for $68.85 \%$ of the respondents and that nearly half of the learners engaged in less than $10 \mathrm{~h}$ of online learning per week.

Table 2 summarizes the questionnaire content. As shown in the table, there were 7 constructs that corresponded to 7 variables in the model introduced before. Every construct had several related items, which were framed as questions in the questionnaire. For example, CQ1, 2, 3, 4, and 5 were five related questions of the construct Course Quality. As mentioned above, every question or item had five choices in the questionnaire. 
Table 1. Sample demographics $(n=382)$.

\begin{tabular}{cccc}
\hline Variables & Classification & Frequency & Percentage (\%) \\
\hline \multirow{2}{*}{ Gender } & male & 143 & 37.43 \\
& female & 239 & 62.57 \\
\hline \multirow{2}{*}{ Age } & less than 18 & 3 & 0.79 \\
& $18 \sim 25$ & 287 & 75.13 \\
& $26 \sim 30$ & 73 & 19.11 \\
& $31 \sim 40$ & 16 & 4.19 \\
& $41 \sim 50$ & 3 & 0.79 \\
\hline \multirow{3}{*}{ Occupation } & students & 287 & 75.13 \\
& employees & 52 & 13.61 \\
& civil servants & 16 & 4.19 \\
& teachers & 18 & 4.71 \\
& others & 9 & 2.36 \\
\hline \multirow{3}{*}{ Education level } & high school & 13 & 3.4 \\
& junior college & 40 & 10.47 \\
& undergraduate & 263 & 68.85 \\
& master & 55 & 14.4 \\
& doctoral & 11 & 2.88 \\
\hline Online learning time & $0-10 \mathrm{~h}$ & 197 & 51.57 \\
& $11-20 \mathrm{~h}$ & 115 & 30.1 \\
& $21-30 \mathrm{~h}$ & 46 & 12.04 \\
& more than $31 \mathrm{~h}$ & 24 & 6.28 \\
\hline
\end{tabular}

Table 2. Summary of the questionnaire content.

\begin{tabular}{|c|c|c|}
\hline Construct & & Items \\
\hline \multirow[t]{5}{*}{ Course Quality (CQ) } & CQ1 & The online learning service provides courses I need. \\
\hline & CQ2 & The online learning service provides courses that could help me improve skills. \\
\hline & CQ3 & The online learning service provides courses that are easy to understand. \\
\hline & CQ4 & The online learning service provides courses that demonstrate high reliability. \\
\hline & CQ5 & The online learning service provides courses that are all-dimensional and accurate. \\
\hline \multirow[t]{3}{*}{ Service Quality (SQ) } & SQ1 & The online learning system helps me acquire knowledge more efficiently. \\
\hline & SQ2 & The online learning system provides excellent service to users. \\
\hline & SQ3 & The online learning system can provide quick feedback to my questions. \\
\hline \multirow[t]{4}{*}{ SS Interaction (SSI) } & SSI1 & I can communicate with peer students quickly and easily. \\
\hline & SSI2 & I can communicate with peer students about professional knowledge most of the time. \\
\hline & SSI3 & I have frequent communication with peer students in online learning. \\
\hline & SSI4 & I maintain a close relationship with peer students in online learning. \\
\hline \multirow[t]{5}{*}{ SI Interaction (SII) } & SII1 & I have frequent interaction with instructors during online classes. \\
\hline & SII2 & The instructors provide different ways for learners to interact with instructors. \\
\hline & SII3 & I can get quick feedback from instructors. \\
\hline & SII4 & I can easily communicate with instructors via online learning. \\
\hline & SII5 & The instructors provide professional instruction to counsel learners. \\
\hline \multirow[t]{3}{*}{ SC Interaction (SCI) } & SCI1 & The online learning system helps me understand the learning content more deeply. \\
\hline & SCI2 & The online learning system prompts me to preview and review the learning content on time. \\
\hline & SCI3 & The online learning system inspires my enthusiasm to acquire knowledge. \\
\hline \multirow[t]{4}{*}{ Perceived Value (PV) } & PV1 & The online learning system is useful to me in improving my skills and knowledge. \\
\hline & PV2 & The online learning system plays a significant role in the process of learning. \\
\hline & PV3 & Through the online learning system, I accomplished what I planned to do with this course. \\
\hline & PV4 & $\begin{array}{l}\text { I use the online learning system to gain knowledge more efficiently compared with } \\
\text { traditional ways of learning. }\end{array}$ \\
\hline \multirow[t]{3}{*}{ Continuance Intention (CI) } & CI1 & 1. I will continue to pursue courses online in the future. \\
\hline & $\mathrm{CI} 2$ & 2. I will recommend others to pursue learning courses online in the future. \\
\hline & $\mathrm{CI} 3$ & 3. I will frequently pursue courses online in the future. \\
\hline
\end{tabular}




\subsection{Data Analyses and Results}

Anderson and Garbing have indicated that there can be a rigorous analysis of the measurement model (outer model) and structural model (inner model) when SEM is utilized as the research methodology [51]. The focus of measurement model analysis is the relationship of the observed to the latent variables. In other words, it seeks to verify reliability, convergent validity, and discriminant validity. Convergent validity, an essential parameter in social science research, indicates the degree to which two measures of constructs that theoretically should be related are in fact related, and reflects the correlation of different indicators for the same construct, whereas discriminant validity refers to the degree to which two conceptually similar concepts are in fact distinct.

To examine the measurement model in this study, we employed Partial Least Squares Structural Equation Modeling (PLS-SEM) to perform confirmatory factor analysis (CFA) to determine the reliability, convergent validity, and discriminant validity of the model [51]. The reliability of the measurement model was examined utilizing the composite reliability (CR) value. Fornell and other scholars hold the view that convergent validity should be analyzed using average variance extracted (AVE), composite reliability (CR), Cronbach's alpha (CA), and factor loading values [52]. The factor loading was higher than 0.7 , demonstrating a great model fit.

Table 3 shows that the values of factor loading exceeded the threshold of 0.7. Meanwhile, the values of AVE, CR, and CA should be higher than 0.5, 0.7, and 0.7, respectively $[53,54]$. The result indicates that the AVE ranged from 0.580 to 0.811 , the CR was between 0.847 and 0.928 , and CA ranged from 0.734 to 0.884 . In this case, all these constructs had satisfactory reliability and convergent validity based on criteria cited from Fornell and Larcker [52].

Table 3. Summary of the outer model.

\begin{tabular}{|c|c|c|c|c|c|}
\hline Construct & Items & Factor Loading & AVE & CR & CA \\
\hline \multirow{3}{*}{ CI } & $\mathrm{CI} 1<-\mathrm{CI}$ & 0.908 & \multirow{3}{*}{0.811} & \multirow{3}{*}{0.928} & \multirow{3}{*}{0.884} \\
\hline & $\mathrm{CI} 2<-\mathrm{CI}$ & 0.900 & & & \\
\hline & $\mathrm{CI} 3<-\mathrm{CI}$ & 0.894 & & & \\
\hline \multirow{5}{*}{ CQ } & CQ1 <- CQ & 0.734 & \multirow{5}{*}{0.635} & \multirow{5}{*}{0.897} & \multirow{5}{*}{0.856} \\
\hline & CQ2 <- CQ & 0.769 & & & \\
\hline & CQ3 <- CQ & 0.827 & & & \\
\hline & CQ4 $<-$ CQ & 0.844 & & & \\
\hline & CQ5 <- CQ & 0.805 & & & \\
\hline \multirow{4}{*}{ PV } & PV1 <- PV & 0.839 & \multirow{4}{*}{0.677} & \multirow{4}{*}{0.893} & \multirow{4}{*}{0.841} \\
\hline & PV2 <- PV & 0.827 & & & \\
\hline & PV3 <- PV & 0.853 & & & \\
\hline & PV4 <- PV & 0.770 & & & \\
\hline \multirow{3}{*}{ SCI } & SCI1 <- SCI & 0.848 & \multirow{3}{*}{0.670} & \multirow{3}{*}{0.859} & \multirow{3}{*}{0.754} \\
\hline & $\mathrm{SCI} 2<-\mathrm{SCI}$ & 0.811 & & & \\
\hline & $\mathrm{SCI} 3<-\mathrm{SCI}$ & 0.795 & & & \\
\hline \multirow{5}{*}{ SII } & SII1 <- SII & 0.702 & \multirow{5}{*}{0.619} & \multirow{5}{*}{0.890} & \multirow{5}{*}{0.846} \\
\hline & SII $2<-$ SII & 0.805 & & & \\
\hline & SII $3<-$ SII & 0.829 & & & \\
\hline & SII $4<-$ SII & 0.835 & & & \\
\hline & SII5 <- SII & 0.757 & & & \\
\hline \multirow{3}{*}{ SQ } & $\mathrm{SQ} 1<-\mathrm{SQ}$ & 0.831 & \multirow{3}{*}{0.654} & \multirow{3}{*}{0.849} & \multirow{3}{*}{0.734} \\
\hline & $\widehat{\mathrm{SQ}} 2<-\mathrm{SQ}$ & 0.852 & & & \\
\hline & SQ3 <- SQ & 0.737 & & & \\
\hline \multirow{4}{*}{ SSI } & SSI1 <- SSI & 0.737 & \multirow{4}{*}{0.580} & \multirow{4}{*}{0.847} & \multirow{4}{*}{0.758} \\
\hline & SSI $2<-$ SSI & 0.728 & & & \\
\hline & SSI $3<-$ SSI & 0.809 & & & \\
\hline & SSI $4<-$ SSI & 0.770 & & & \\
\hline
\end{tabular}

Notes: $\mathrm{CI}=$ Continuance Intention; $\mathrm{CQ}=$ Course Quality; PV = Perceived Value; $\mathrm{SCI}=\mathrm{SC}$ Interaction; SII = SI Interaction; $\mathrm{SQ}=$ Service Quality; SSI = SS Interaction. 
Discriminant reliability is primarily examined by two methods. The first criterion is that the square root of the AVE value should exceed the values of correlation constructs, which can be manifested in the inter-construct correlations in Table 4, indicating satisfactory discriminant validity $[55,56]$. The second criterion relates to a comparison between the values of the constructs' item loading and cross loading of other variables. Cross loading implies how strongly each target item loads on the non-target factors. Table 5 shows that all of the item loading values were higher than the cross-loading values of potential variables. In this case, the discriminant validity of all the constructs is considered to be significant. It also indicates that each construct in the model was actually distinct and had sufficient discriminant validity. Among all the item loadings in the table, the Course Quality (CQ) values are the highest, which implies that the correlation between the items and construct is the highest.

Table 4. Inter-construct correlations.

\begin{tabular}{cccccccc}
\hline & CI & CQ & PV & SCI & SII & SQ & SSI \\
\hline CI & 0.901 & & & & & & \\
CQ & 0.504 & 0.797 & & & & & \\
PV & 0.722 & 0.571 & 0.823 & & & & \\
SCI & 0.081 & 0.066 & 0.088 & 0.818 & & & \\
SII & 0.437 & 0.420 & 0.542 & 0.039 & 0.787 & & \\
SQ & 0.495 & 0.639 & 0.562 & 0.038 & 0.497 & 0.808 & \\
SSI & 0.112 & 0.066 & 0.069 & 0.643 & 0.049 & 0.039 & 0.762 \\
\hline
\end{tabular}

Table 5. Results of factor analysis with overall samples.

\begin{tabular}{cccccccc}
\hline & CI & CQ & PV & SCI & SII & SQ & SSI \\
\hline CI1 & 0.908 & 0.487 & 0.677 & 0.075 & 0.400 & 0.466 & 0.087 \\
CI2 & 0.900 & 0.431 & 0.624 & 0.045 & 0.430 & 0.431 & 0.104 \\
CI3 & 0.894 & 0.443 & 0.648 & 0.099 & 0.353 & 0.441 & 0.113 \\
\hline CQ1 & 0.369 & 0.734 & 0.363 & 0.078 & 0.286 & 0.430 & 0.058 \\
CQ2 & 0.449 & 0.769 & 0.431 & 0.098 & 0.294 & 0.464 & 0.112 \\
CQ3 & 0.383 & 0.827 & 0.456 & 0.045 & 0.331 & 0.508 & 0.094 \\
CQ4 & 0.400 & 0.844 & 0.523 & 0.056 & 0.375 & 0.543 & 0.034 \\
CQ5 & 0.413 & 0.805 & 0.484 & 0.000 & 0.375 & 0.582 & -0.020 \\
\hline PV1 & 0.583 & 0.504 & 0.839 & 0.079 & 0.468 & 0.511 & 0.062 \\
PV2 & 0.608 & 0.497 & 0.827 & 0.076 & 0.463 & 0.455 & 0.014 \\
PV3 & 0.591 & 0.528 & 0.853 & 0.066 & 0.492 & 0.516 & 0.053 \\
PV4 & 0.599 & 0.337 & 0.770 & 0.067 & 0.350 & 0.355 & 0.105 \\
\hline SCI1 & 0.035 & 0.029 & 0.041 & 0.848 & 0.039 & 0.004 & 0.594 \\
SCI2 & 0.075 & 0.086 & 0.143 & 0.811 & 0.047 & 0.071 & 0.458 \\
SCI3 & 0.097 & 0.054 & 0.041 & 0.795 & 0.010 & 0.026 & 0.513 \\
\hline SII1 & 0.275 & 0.200 & 0.375 & 0.070 & 0.702 & 0.300 & 0.053 \\
SII2 & 0.312 & 0.348 & 0.410 & 0.080 & 0.805 & 0.380 & 0.100 \\
SII3 & 0.347 & 0.348 & 0.398 & 0.014 & 0.829 & 0.418 & 0.029 \\
SII4 & 0.392 & 0.371 & 0.487 & -0.011 & 0.835 & 0.424 & -0.004 \\
SII5 & 0.379 & 0.363 & 0.450 & 0.013 & 0.757 & 0.417 & 0.023 \\
\hline SQ1 & 0.429 & 0.578 & 0.510 & 0.049 & 0.369 & 0.831 & 0.022 \\
SQ2 & 0.405 & 0.577 & 0.464 & 0.061 & 0.394 & 0.852 & 0.021 \\
SQ3 & 0.365 & 0.374 & 0.379 & -0.027 & 0.456 & 0.737 & 0.056 \\
\hline SSI1 & 0.108 & -0.004 & 0.047 & 0.492 & 0.025 & 0.044 & 0.737 \\
SSI2 & 0.073 & 0.041 & 0.010 & 0.465 & 0.041 & -0.011 & 0.728 \\
SSI3 & 0.075 & 0.110 & 0.088 & 0.514 & 0.077 & 0.087 & 0.809 \\
SSI4 & 0.086 & 0.049 & 0.060 & 0.485 & 0.003 & -0.007 & 0.770 \\
\hline & & & & & & & \\
\hline
\end{tabular}


Regarding the analysis of the structural model in this study, the model's goodness of fit and overall explanatory power were considered. Goodness-of-fit analysis refers to how well a model fits a set of observations. Table 6 lists some fit indexes, recommended values, and real results of this study. The fit indexes are as follows: the chi-square statistics minimum discrepancy per degree of freedom (CMIN/DF) is 1.961; goodness-of-fit index (GFI), 0.895; adjusted goodness-of-fit index (AGFI), 0.874; comparative fit index (CFI), 0.938; and root mean squared error approximation (RMSEA), 0.05. They all meet the recommended values for the indexes [57].

Table 6. Indicators of model's goodness of fit.

\begin{tabular}{ccc}
\hline Fit Index & Recommended Value & Results in This Study \\
\hline CMIN & & 617.668 \\
DF & $\leq 3.0$ & 315 \\
Chi-square Statistic CMIN/DF & $\geq 0.80$ & 1.961 \\
GFI & $\geq 0.80$ & 0.895 \\
AGFI & $\geq 0.90$ & 0.874 \\
CFI & $\leq 0.08$ & 0.938 \\
RMSEA & 0.05 \\
\hline
\end{tabular}

\subsection{Hypothesis Test Results}

As for the analysis of the standardized path coefficient, as shown in Table 7, the CR value should be higher than 1.96, and the path is proved to be significant when the $p$ value is less than 0.05. It is evident that Hypotheses 7 and 8 are not acceptable. Additionally, in Figure 2, the R-squared value demonstrates the model's explanatory power for every variable. The overall explanatory power of the model in this study has an R-squared value of $68.5 \%$ for continuance intentions in online learning. Service quality has an R-squared value of $64.9 \%$ and perceived value of $60.5 \%$, implying an acceptable power of this model to explain continuance intentions in an online learning environment.

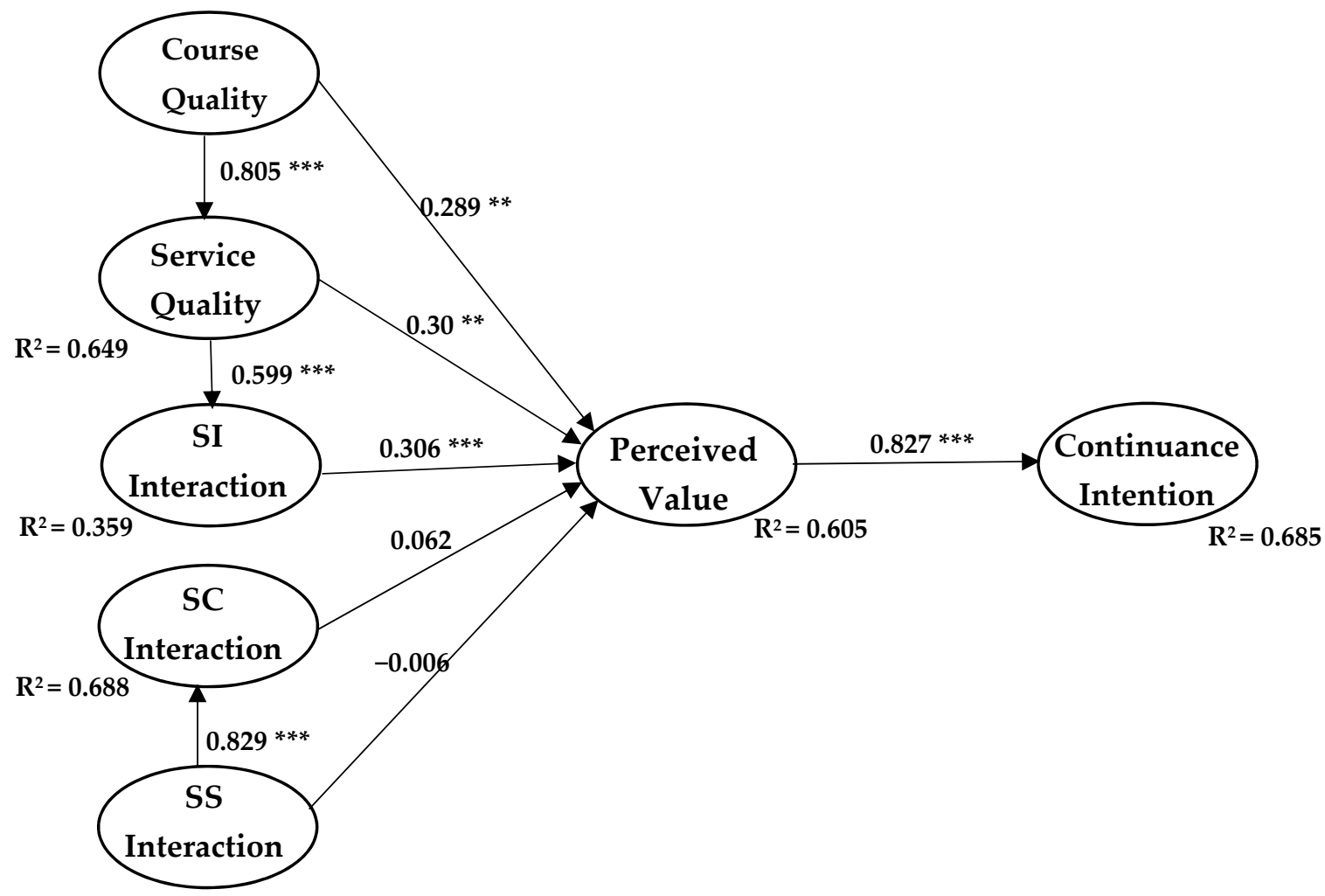

Figure 2. Results of the research model tests. Notes: ${ }^{* *} p<0.01 ;{ }^{* * *} p<0.001$. 
Table 7. Standardized estimates.

\begin{tabular}{|c|c|c|c|c|c|c|c|c|}
\hline $\mathbf{H \#}$ & & Path & & S.E. & $\begin{array}{c}\text { C.R. } \\
(>1.96)\end{array}$ & $p$ & $\begin{array}{c}\text { Standardized } \\
\text { Path Coefficient }\end{array}$ & $\mathbf{Y} / \mathbf{N}$ \\
\hline H1 & Service Quality & $<-$ & Course Quality & 0.087 & 10.292 & $* * *$ & 0.805 & Yes \\
\hline $\mathrm{H} 2$ & SI Interaction & $<-$ & Service Quality & 0.074 & 8.182 & $* * *$ & 0.599 & Yes \\
\hline $\mathrm{H} 3$ & SC Interaction & $<-$ & SS Interaction & 0.112 & 9.632 & $* * *$ & 0.829 & Yes \\
\hline $\mathrm{H} 4$ & Perceived Value & $<-$ & Course Quality & 0.127 & 2.919 & $0.004^{* *}$ & 0.289 & Yes \\
\hline H5 & Perceived Value & $<-$ & Service Quality & 0.132 & 2.602 & $0.009^{* *}$ & 0.3 & Yes \\
\hline H6 & Perceived Value & $<-$ & SI Interaction & 0.073 & 4.784 & $* * *$ & 0.306 & Yes \\
\hline $\mathrm{H7}$ & Perceived Value & $<-$ & SC Interaction & 0.106 & 0.539 & 0.59 & 0.062 & No \\
\hline H8 & Perceived Value & $<-$ & SS Interaction & 0.137 & -0.056 & 0.955 & -0.006 & No \\
\hline H9 & Continuance Intention & $<-$ & Perceived Value & 0.069 & 14.333 & $* * *$ & 0.827 & Yes \\
\hline
\end{tabular}

Notes: ${ }^{* *} p<0.01 ; * * *<0.001$

\section{Discussion}

As a new learning mode, online education has the characteristics of openness, repeatability, low cost, etc., which provide a new opportunity for educational reform and innovation in the Internet era. The principal issue in online education at present is the high dropout rate of online learners. While we recognize the significance of online education today, it is still necessary to explore the issue of continuance intentions in an online learning environment. Based on the results of the analyses in this study, the following findings were obtained:

The relationship between variables is also an important aspect that cannot be ignored. The testing results in Section 3 demonstrate that $\mathrm{H1}, 2$, and 3 are confirmed, implying that course quality, service quality, and student-instructor interaction have correlations and influences with each other. Student-student interaction was found to have a positive effect on student-content interaction. The results obtained also show that H4, 5, and 6 are supported, demonstrating that course quality, service quality, and student-instructor interaction are secondary determinants of online learners' continuance intentions, and these variables had a direct effect on online learners' perceived value. The results supported Hone's research, which reported the factors affecting MOOC retention and found that MOOC course content and interaction with instructors were significant predictors for MOOC retention [19]. Meanwhile, this result was also consistent with many prior studies. Dağhan et al. suggested an association between overall quality variables, perceived value, and continuance intentions in online learning [11]. Wang, Y.S. proposed an updated IS success model in the context of studying e-commerce system success, and showed that service quality had a strong effect on perceived value, which also positively influenced intention to use in system success. Thus, our study partially supports the conclusions of Wang's research [58]. Cronin et al. assessed the influence of the drivers of quality, value, and satisfaction on behavioral intentions, which empirically verified that service quality had an indirect influence on intention to use [59]. Teas et al. built on a conceptual model to test the influence of extrinsic cues on perceived quality, perceived value, and perceived sacrifice. The results indicated that perceived quality was a direct antecedent of perceived value, which would also act on purchase intentions in commerce [60]. Bolton et al. developed a multistage model for assessing service quality and value for customers, and this study concluded that customers' appraisal of service value was positively correlated with their assessment of service quality [61]. Cyr et al. examined the essential impact of perceived interactivity on e-loyalty and concluded that perceived interactivity positively influenced the e-loyal behavior of online users [62].

Regarding the second research question in this study, $\mathrm{H7}$ and 8 were not confirmed, indicating that student-content interaction and student-student interaction did not directly influence the perceived value for online learners. This result prompts us to further analyze and compare the different effects of three interaction modes on perceived value and continuance retention. Of the three kinds of interactions in online learning, student- 
instructor interaction has the most substantial influence on perceived value. The reason is that when students pursue online education, the most frequent mode of interaction is that between students and teachers. Student-student interaction and student-content interaction are less utilized compared with student-instructor interaction because those two types of interactions require self-control capability. H9 was supported, revealing that the influence of perceived value on online learners' continuance intentions is strongly positive, and perceived value is a mediator factor in this model. Before pursuing online classes, students tend to have expectations about the courses, which can be considered as perceived value. The matter of whether learners can persist in completing online learning is closely related to their perceived value of online education. The impact of perceived value on continuous learning behavior is supported by the empirical data in this study, which are also consistent with the findings of other research.

This result was also consistent with the research conclusion of Brady and Robertson, who showed that perceived value was the primary factor influencing purchase intentions in the study of service value in the USA and educators [20]. Yang et al. predicted citizens' mobile government microblog continuance in their study [63]. Although it examined the theme of citizens' government microblog continuance, it belongs to the study of information system continuous intention; thus, our study has some similarities with it. Yang et al.'s study concluded that social influence, perceived interactivity, and perceived mobility positively influenced citizens' perceived value, which further affected their continuous retention. Therefore, our study results are also consistent with it. The results in our study also support much literature in this area. Parasuraman et al. summarized the qualityvalue-loyalty linkage in which service quality promotes perceived value, which, in turn, is beneficial for purchasing loyalty [64]. Kim et al. explored the relationships among website quality, perceived value, information quality, and intention to use in an online shopping environment, and showed that perceived value had a positive effect on users' loyalty intentions toward apparel online shopping websites [65]. Fassnacht et al. investigated the significance of service in the context of web-based services, and the results show that web-based service quality is a positive driver of desired behavior intentions mediated by perceived value [66]. Harris et al. conducted research on four dimensions of loyalty and constructed a model by synthesizing the concepts of value, quality, trust, satisfaction, and loyalty. The study proposed that perceived value exhibited both direct and indirect relationships with continuous loyalty [67].

\section{Conclusions}

\subsection{Theoretical Implications}

This study provides critical thinking for model construction and contributes to the theoretical literature in this field. We consider not only the relationship between horizontal variables but also the correlations between vertical variables. For instance, information system success theory has been frequently analyzed as a significant factor influencing online learners' continuance of use. In this study, course quality replaced information quality in order to emphasize its pedagogical implications in the context of online education. On the basis of the information system success theoretical perspective, the correlation between course quality and service quality was also considered in the construction of the model, which is a supplement to IS success theory, and our study also proposed a relationship between student-content interaction and student-student interaction so as to have a deep understanding of interaction theory.

\subsection{Practical Implications}

The findings in this study offer new insights and practical implications for online learning platform managers, instructors, and learners themselves. The conclusions show that the variables of service quality and course quality have great influences on learners' perceived value and continuous pursuit of online courses. If the online learning platforms are able to offer services and courses that make learners perceive the value of pursuing 
online courses, this would help learners to persist in taking these courses, so online learning platform practitioners should attach importance to the construction of attractive and high-quality institutions that facilitate user retention [66]. Regarding improving service quality, online learning platform managers could pay more attention to learners' feedback and reflection on courses and platform management [13]. Many scholars have proposed that information recipients have the right to choose what information they would like to receive. Too much information could result in aversion to the curriculum. Therefore, some information such as too much advertisement on platforms during online classes should be avoided [47]. Thus, platform developers ought to avoid too much advertising in the classroom and transform the methods of advertising. Apart from this advice, online learning platforms should strengthen management and monitoring, optimize communication channels, and improve the supervision mechanism [47].

To enhance course quality, it is critical to develop a blended teaching approach that combines online and offline teaching modes. In the context of blended learning, it is essential to cultivate learners' self-regulated learning ability, and self-regulated learning could be supervised by computer-based instruction, interactions, and feedback [68]. Online learning platforms should also urge parents to supervise their children to ensure they complete the learning tasks in time, and they ought to improve learners' learning supervision mechanism after online classes. The key to the promotion of online and offline blended learning lies not in the application of technology, but in the efficacy of instructors and innovativeness of teaching mechanisms and evaluation systems in the online environment, with an emphasis on encouraging instructors to apply the blended teaching mode. Instructors should improve their professional skills, change their teaching methodology if necessary, strive to increase courses' interest, and enhance interactions with students to improve their concentration in class [13].

According to the findings in this study, student-instructor interaction has the most substantial influence on perceived value among three types of interactions in online learning, which indicates that SI interaction should be emphasized for the continuous use of online learning. This conclusion is significant, as it will serve as a focus area for future research in this field. Apart from classroom interactions between learners and instructors, it is crucial to expand communication channels and maintain the frequency of contact such as by organizing SNS (Social Network Software) groups to communicate with learners and collecting questions that learners cannot understand to solve in detail in the class [69]. As for students, they should cultivate the spirit of active participation in their courses, have clear learning motivations, improve their self-control, and actively communicate with teachers and other classmates [68].

This study also draws attention to perceived value, owing to its positive effect on mediation. Hence, online learning practitioners must take notice of the fact that perceived value is a major determinant of the retention of online learners. If learners perceive the value of online courses in various aspects, it will bring more and more favorable comments, promote students' continuous learning, and bring more business value $[58,63]$.

\subsection{Research Limitations and Future Study}

Due to the constraints of time and energy, this study has several limitations. First, valid data were collected from 382 respondents, which is more than 10 times the 27 questions included in the questionnaire. About $60 \%$ of the respondents were female, and most of the respondents were students or youth, indicating disproportion in terms of occupation, gender, and age, which, to some extent, affected the universality of the subjects. At the time of the questionnaire survey, the electronic responses were mainly collected from the professional website. Thus, the characteristics of the learners' diversity could not be determined in the study, resulting in the lack of representativeness of the sample, which may have further affected the accuracy and authenticity of the research results. Thus, the universality of the respondents is a significant factor to control in a future study. Furthermore, the online learning needs of learners are different, so a wider group of 
learners should be selected for future research, and various approaches should be used to collect questionnaires.

Another drawback is that this study focused on online learning continuance among Chinese users and did not include users in other countries. Therefore, further study may collect statistics from different countries to test the reasonability of the constructed model. Last but not least, this study analyzed the influencing factors and mechanisms of users' continuance intentions on the basis of the information systems success model, the modes of interactions, and perceived value. However, online learners' continuance behavior is affected by many factors. The theoretical model of this study cannot cover all the influencing factors. Other variables influencing online learners' continuous use will be explored, and various statistical analysis methods will also be applied in the studies to make the results more accurate and persuasive.

Regarding other future work in this field, the comparison of different areas in China, such as east and west, is also a meaningful direction because there is a great difference in development between these two areas in many aspects. Additionally, blended learning has been developed at various levels of traditional campus-based education to date as a response to technical advances [70]. Thus, it is also worth exploring a deep analysis of blended learning in the context of online learning, especially for higher education, in a future study.

Author Contributions: Conceptualization, Y.L.; methodology, Y.L.; software, Y.L.; formal analysis, Y.L., N.N., H.Y., and H.-S.P.; investigation, Y.L.; data curation, Y.L.; supervision, N.N., H.Y., and H.-S.P. All authors have read and agreed to the published version of the manuscript.

Funding: This research received no external funding.

Institutional Review Board Statement: The study was conducted according to the guidelines of the Declaration of Helsinki.

Informed Consent Statement: Informed consent was obtained from all subjects involved in the study.

Acknowledgments: The authors would like to express their sincere gratitude to Liqing Zang for her assistance. We also thank the editors and anonymous reviewers for their valuable advice.

Conflicts of Interest: The authors declare no conflict of interest.

\section{References}

1. Sustainable Development Goals (SDGs). Available online: https://www.who.int/health-topics/sustainable-development-goals\# tab=tab_1 (accessed on 1 July 2010).

2. Burmeister, M.; Rauch, F.; Eilks, I. Education for Sustainable Development (ESD) and chemistry education. Chem. Educ. Res. Pract. 2012, 13, 59-68. [CrossRef]

3. Isaac, O.; Aldholay, A.; Abdullah, Z.; Ramayah, T. Online learning usage within Yemeni higher education: The role of compatibility and task-technology fit as mediating variables in the IS success model. Comput. Educ. 2019, 136, 113-129. [CrossRef]

4. Moore, J.L.; Dickson-Deane, C.; Galyen, K. e-Learning, online learning, and distance learning environments: Are they the same? Internet High. Educ. 2011, 14, 129-135. [CrossRef]

5. 100 Essential e-Learning Statistics for 2020. Available online: https:/ / e-student.org/e-learning-statistics / (accessed on 2 February 2020).

6. China Online Education Market Data Release Report: 2020Q1\&2020Q2e. Available online: https://www.iresearch.com.cn/ Detail $/$ report?id=3561\&isfree $=0 b$ (accessed on 1 April 2020).

7. Simpson, O. 22\%-Can We Do Better, The CWP Retention Literature Review Final Report. July 2010. Available online: http: / / www.ormondsimpson.com/index.html (accessed on 1 July 2010).

8. Perna, L.; Ruby, A.; Boruch, R.; Wang, N.; Scull, J.; Evans, C.; Ahmad, S. The life cycle of a million MOOC users. In Proceedings of the MOOC Research Initiative Conference, University of Pennsylvania, Philadelphia, PA, USA, 5 December 2013.

9. Allen, I.E.; Seaman, J. Changing Course: Ten Years of Tracking Online Education in the United States; Sloan Consortium: Newburyport, MA, USA, 2013; pp. 154-196.

10. Lee, M.C. Explaining and predicting users' continuance intention toward e-learning: An extension of the expectationConfirmation model. Comput. Educ. 2010, 54, 506-516. [CrossRef]

11. Dağhan, G.; Akkoyunlu, B. Modeling the continuance usage intention of online learning environments. Comput. Hum. Behav. 2016, 60, 198-211. [CrossRef] 
12. Aldholay, A.H.; Isaac, O.; Abdullah, Z.; Ramayah, T. The role of transformational leadership as a mediating variable in DeLone and McLean information system success model: The context of online learning usage in Yemen. Telemat. Inform. 2018, 35, 1421-1437. [CrossRef]

13. Mohammadi, H. Factors affecting the e-learning outcomes: An integration of TAM and IS success model. Telemat. Inform. 2015, 32, 701-719. [CrossRef]

14. Sun, P.C.; Tsai, R.J.; Finger, G.; Chen, Y.Y.; Yeh, D. What drives a successful e-Learning? An empirical investigation of the critical factors influencing learner satisfaction. Comput. Educ. 2008, 50, 1183-1202. [CrossRef]

15. Liu, N.; Pu, Q. Factors influencing learners' continuance intention toward one-to-one online learning. Interact. Learn. Environ. 2020, 1-22. [CrossRef]

16. Liu, I.F.; Chen, M.C.; Sun, Y.S.; Wible, D.; Kuo, C.H. Extending the TAM model to explore the factors that affect intention to use an online learning community. Comput. Educ. 2010, 54, 600-610. [CrossRef]

17. Wang, Z.; Chen, L.; Anderson, T. A framework for interaction and cognitive engagement in connectivist learning contexts. Int. Rev. Res. Open Distrib. Learn. 2014, 15, 121-141. [CrossRef]

18. You, J.W.; Kang, M. The role of academic emotions in the relationship between perceived academic control and self-regulated learning in online learning. Comput. Educ. 2014, 77, 125-133. [CrossRef]

19. Hone, K.S.; El Said, G.R. Exploring the factors affecting MOOC retention: A survey study. Comput. Educ. 2016, 98, 157-168. [CrossRef]

20. Tam, J.L.M. Customer satisfaction, service quality and perceived value: An integrative model. J. Market. Manag. 2004, 20 , 897-917. [CrossRef]

21. Kumar, P.; Kumar, A.; Palvia, S.; Verma, S. Online business education research: Systematic analysis and a conceptual model. Int. J. Manag. Educ.-Oxf. 2019, 17, 26-35. [CrossRef]

22. Tsai, Y.H.; Lin, C.H.; Hong, J.C.; Tai, K.H. The effects of metacognition on online learning interest and continuance to learn with MOOCs. Comput. Educ. 2018, 121, 18-29. [CrossRef]

23. Dai, H.M.; Teo, T.; Rappa, N.A.; Huang, F. Explaining Chinese university students' continuance learning intention in the MOOC setting: A modified expectation confirmation model perspective. Comput. Educ. 2020, 150, 103850. [CrossRef]

24. Jeyaraj, A. DeLone \& McLean models of information system success: Critical meta-review and research directions. Int. J. Inf. Manag. 2020, 54, 102-139.

25. Delone, W.H.; McLean, E.R. The DeLone and McLean model of information systems success: A ten-year update. J. Manag. Inform. Syst. 2003, 19, 9-30.

26. Petter, S.; DeLone, W.; McLean, E. Measuring information systems success: Models, dimensions, measures, and interrelationships. Eur. J. Inform. Syst. 2008, 17, 236-263. [CrossRef]

27. Chung, N.; Lee, H.; Lee, S.J.; Koo, C. The influence of tourism website on tourists' behavior to determine destination selection: A case study of creative economy in Korea. Technol. Forecast. Soc. Chang. 2015, 96, 130-143. [CrossRef]

28. Yang, M.; Shao, Z.; Liu, Q.; Liu, C. Understanding the quality factors that influence the continuance intention of students toward participation in MOOCs. ETRED-Educ. Tech. Res. 2017, 65, 1195-1214.

29. Li, Y.; Duan, Y.; Fu, Z.; Alford, P. An empirical study on behavioural intention to reuse e-learning systems in rural China. Br. J. Educ. Technol. 2012, 43, 933-948. [CrossRef]

30. Huang, H.M. Toward constructivism for adult learners in online learning environments. Brit. J. Educ. Technol. 2002, 33, 27-37. [CrossRef]

31. Zhu, Y.; Zhang, J.H.; Au, W.; Yates, G. University students' online learning attitudes and continuous intention to undertake online courses: A self-regulated learning perspective. ETRED-Educ. Tech. Res. 2020, 68, 1-35.

32. Wagner, E.D. In support of a functional definition of interaction. Am. J. Distance Educ. 1994, 8, 6-29. [CrossRef]

33. Martin, D.P.; Rimm-Kaufman, S.E. Do student self-efficacy and teacher-student interaction quality contribute to emotional and social engagement in fifth grade math? J. Sch. Psychol. 2015, 53, 359-373. [CrossRef]

34. Ma, Y.; Ruangkanjanases, A.; Chen, S.C. Investigating the Impact of Critical Factors on Continuance Intention towards CrossBorder Shopping Websites. Sustainability 2019, 11, 5914. [CrossRef]

35. Parker, C.; Mathews, B.P. Customer satisfaction: Contrasting academic and consumers' interpretations. Mark. Intell. Plan. 2001, 19, 38-44. [CrossRef]

36. Yang, Z.; Peterson, R.T. Customer perceived value, satisfaction, and loyalty: The role of switching costs. Psychol. Mark. 2004, 21, 799-822. [CrossRef]

37. Ma, S.C.; Kaplanidou, K. Service quality, perceived value and behavioral intentions among highly and lowly identified baseball consumers across nations. Int. J. Sport Mark. Spo. 2019, 21, 46-69. [CrossRef]

38. Konuk, F.A. The role of store image, perceived quality, trust and perceived value in predicting consumers' purchase intentions towards organic private label food. J. Retail. Consum. Serv. 2018, 43, 304-310. [CrossRef]

39. Kuo, Y.F.; Wu, C.M.; Deng, W.J. The relationships among service quality, perceived value, customer satisfaction, and post-purchase intention in mobile value-added services. Comput. Hum. Behav. 2009, 25, 887-896. [CrossRef]

40. Overby, J.W.; Lee, E.J. The effects of utilitarian and hedonic online shopping value on consumer preference and intentions. J. Bus. Res. 2006, 59, 1160-1166. [CrossRef]

41. Boksberger, P.E.; Melsen, L. Perceived value: A critical examination of definitions, concepts and measures for the service industry. J. Serv. Mark. 2011, 25, 229-240. [CrossRef] 
42. Currás-Pérez, R.; Dolz-Dolz, C.; Miquel-Romero, M.J.; Sánchez-García, I. How social, environmental, and economic CSR affects consumer-perceived value: Does perceived consumer effectiveness make a difference? Corp. Soc. Responsib. Environ. Manag. 2018, 25, 733-747. [CrossRef]

43. Alruwaie, M.; El-Haddadeh, R.; Weerakkody, V. A framework for evaluating citizens' expectations and satisfaction toward continued intention to use e-government services. In Proceedings of the International Conference on Electronic Government, Kristiansand, Norway, 3-6 September 2012; Springer: Berlin/Heidelberg, Germany, 2012; pp. 273-286.

44. Neufeld, J.E.; Rasmussen, H.N.; Lopez, S.J.; Ryder, J.A.; Magyar-Moe, J.L.; Ford, A.I.; Bouwkamp, J.C. The engagement model of person-environment interaction. Couns. Psychol. 2006, 34, 245-259. [CrossRef]

45. Aydemir, E.; Sahin, Y. Evaluation of healthcare service quality factors using grey relational analysis in a dialysis center. Grey Syst. 2019, 9, 432-448. [CrossRef]

46. Roca, J.C.; Chiu, C.M.; Martínez, F.J. Understanding e-learning continuance intention: An extension of the Technology Acceptance Model. Int. J. Hum.-Comput. St. 2006, 64, 683-696. [CrossRef]

47. Wang, H.C.; Chiu, Y.F. Assessing e-learning 2.0 system success. Comput. Educ. 2011, 57, 1790-1800. [CrossRef]

48. Ulaga, W.; Chacour, S. Measuring customer-perceived value in business markets: A prerequisite for marketing strategy development and implementation. Ind. Market Manag. 2001, 30, 525-540. [CrossRef]

49. Wang, C.; Teo, T.S.H.; Liu, L. Perceived Value and Continuance Intention in Mobile Government Service in China. Telemat. Inform. 2020, 48, 101348. [CrossRef]

50. Martínez-Navalón, J.G.; Gelashvili, V.; Debasa, F. The impact of restaurant social media on environmental sustainability: An empirical study. Sustainability 2019, 11, 6105. [CrossRef]

51. Srinivasan, M.; Srivastava, P.; Iyer, K.N. An empirical model of salesperson competence, buyer-seller trust and collaboration: The moderating role of technological turbulence and product complexity. J. Market. Theory Prac. 2020, 28, 447-459. [CrossRef]

52. Humbani, M.; Wiese, M. An integrated framework for the adoption and continuance intention to use mobile payment apps. Int. J. Bank Mark. 2019, 37, 646-664. [CrossRef]

53. Gogan, I.C.W.; Zhang, Z.; Matemba, E.D. Impacts of gratifications on consumers' emotions and continuance use intention: An empirical study of Weibo in China. Sustainability 2018, 10, 3162. [CrossRef]

54. Zhou, T. An empirical examination of continuance intention of mobile payment services. Decis. Support Syst. 2013, 54, 1085-1091. [CrossRef]

55. Dalvi-Esfahani, M.; Wai Leong, L.; Ibrahim, O.; Nilashi, M. Explaining students' continuance intention to use Mobile web 2.0 learning and their perceived learning: An integrated approach. J. Educ. Comput. Res. 2020, 57, 1956-2005. [CrossRef]

56. Po-An Hsieh, J.J.; Wang, W. Explaining employees' extended use of complex information systems. Eur. J. Inform. Syst. 2007, 16, 216-227. [CrossRef]

57. Pang, S.; Bao, P.; Hao, W.; Kim, J.; Gu, W. Knowledge Sharing Platforms: An Empirical Study of the Factors Affecting Continued Use Intention. Sustainability 2020, 12, 2341. [CrossRef]

58. Wang, Y.S. Assessing e-commerce systems success: A respecification and validation of the DeLone and McLean model of IS success. Inform. Syst. J. 2008, 18, 529-557. [CrossRef]

59. Cronin, J.J., Jr.; Brady, M.K.; Hult, G.T.M. Assessing the effects of quality, value, and customer satisfaction on consumer behavioral intentions in service environments. J. Retail. 2000, 76, 193-218. [CrossRef]

60. Teas, R.K.; Sanjeev, A. The effects of extrinsic product cues on consumers' perceptions of quality, sacrifice, and value. J. Acad. Market. Sci. 2000, 28, 278-290. [CrossRef]

61. Bolton, R.N.; Drew, J.H. A multistage model of customers' assessments of service quality and value. J. Consum. Res. 1991, 17, 375-384. [CrossRef]

62. Cyr, D.; Head, M.; Ivanov, A. Perceived interactivity leading to e-loyalty: Development of a model for cognitive-affective user responses. Int. J. Hum.-Comput. St. 2009, 67, 850-869. [CrossRef]

63. Yang, S.; Zeng, X. Sustainability of government social media: A multi-analytic approach to predict citizens' mobile government microblog continuance. Sustainability 2018, 10, 4849. [CrossRef]

64. Parasuraman, A.; Grewal, D. The impact of technology on the quality-value-loyalty chain: A research agenda. J. Acad. Market. Sci. 2000, 28, 168-174. [CrossRef]

65. Kim, H.; Niehm, L.S. The impact of website quality on information quality, value, and loyalty intentions in apparel retailing. J. Interact. Mark. 2009, 23, 221-233. [CrossRef]

66. Fassnacht, M.; Köse, I. Consequences of Web-based service quality: Uncovering a multi-faceted chain of effects. J. Interact. Mark. 2007, 21, 35-54. [CrossRef]

67. Harris, L.C.; Goode, M.M. The four levels of loyalty and the pivotal role of trust: A study of online service dynamics. J. Retail. 2004, 80, 139-158. [CrossRef]

68. Barnard, L.; Lan, W.Y.; To, Y.M.; Paton, V.O.; Lai, S.L. Measuring self-regulation in online and blended learning environments. Internet High. Educ. 2009, 12, 1-6. [CrossRef]

69. Dennen, V.P.; Aubteen, D.A.; Smith, L.J. Instructor-learner interaction in online courses: The relative perceived importance of particular instructor actions on performance and satisfaction. Distance Educ. 2007, 28, 65-79. [CrossRef]

70. Evans, J.C.; Yip, H.; Chan, K.; Armatas, C.; Tse, A. Blended learning in higher education: Professional development in a Hong Kong university. High. Educ. Res. Dev. 2020, 39, 643-656. [CrossRef] 